\title{
Prevalence and correlates of multiple sexual partnerships among private college students in Bahir dar city, northwest Ethiopia
}

\author{
Zelalem Alamrew Anteneh \\ Department of Public Health, College of Medicine and Health Sciences, Bahir Dar University, PO-Box 79, Ethiopia
}

Email address:

kzolam@gmail.com (Z. A. Anteneh)

To cite this article:

Zelalem Alamrew Anteneh. Prevalence and Correlates of Multiple Sexual Partnerships among Private College Students in Bahir Dar City, Northwest Ethiopia, Science Journal of Public Health. Vol. 1, No. 1, 2013, pp. 9-17. doi: 10.11648/j.sjph.20130101.12

\begin{abstract}
Background: Multiple sexual partnership is having two or more sexual partners that overlapped in time; individuals who have concurrent sexual partners increase their risk of HIV infections. The aim of the study was to assess the prevalence and correlates of multiple sexual partnerships among private college students in Bahir dar city. Methods: A cross sectional study was conducted in Oct. 2012 among 790 private college students of Bahir Dar city using multistage sampling technique. A pre-tested self-administered questionnaire was used to collect the data. The data were coded, entered, cleaned and analyzed using univariate, bivariate and multivariate analysis with SPSS version 16 soft ware package. Results: About $50.7 \%$ of respondents were sexually active. Multiple sexual partnerships were reported by $45.3 \%$ of sexually active respondents. Male respondents were more likely to have multiple sexual partners compared to females (AOR=4.76; $\mathrm{CI}: 3.02-7.51)$, students who were living alone in rented house were about two times more likely to have multiple sexual partners compared to those live with their family ( $\mathrm{AOR}=2.02$; CI: 1.25-3.27). Besides, students who have peer pressure were about six times more likely to have multiple sexual partners compared to those don't have (AOR=5.99;CI: 3.66-9.81). Moreover, respondents who drank alcohol were more likely to have multiple sex partners compared to those who never drank $(\mathrm{AOR}=3.20$; $\mathrm{CI}$ : 2.02- 5.08). Conclusion: Large proportions of students engaged in multiple sexual partnerships. There were variables associated with multiple sexual partnerships. Therefore, interventions targeting on these factors were recommended.
\end{abstract}

Keywords: Multiple Sexual Partners, Ethiopia, Adolescents And Young Adults

\section{Background}

Multiple sexual partnerships is having two or more sexual partners that overlapped in time; individuals who have concurrent sexual partners increase their risk of contracting HIV/AIDS, and multiple sexual partnerships have been identified as a key driver of HIV transmission.[1- 2] Several studies declared that the risk of HIV infection increases with concurrent sexual partners in a dense sexual network by allowing the virus to spread rapidly to others.[3- 5]

Currently a notable decline of new HIV infections observed in sub Saharan Africa, but the region is still disproportionately hit by the virus accounting the largest burden of the disease. In 2010 about $70 \%$ of new HIV infections and $68 \%$ of all people living with the virus resided in the region. [6]; besides, concurrent sexual partnerships were suggested as a possible explanation for why HIV epidemics are so much more severe in sub-Saharan Africa than elsewhere in the world.[4]

It is evident that multiple sexual partnerships are a risky sexual behaviour in which youth engaged.[7] Accordingly, studies conducted in different parts of Africa among adolescents and young adults declared that having multiple sexual partners in these segments of population is fairly common.[8-10]

Studies indicated that substance use, religiosity and gender were correlated with multiple sexual partner ships; accordingly, alcohol and Chat (green leaf) consumption were associated with higher risk for having higher number of sexual partners.[11-13]

Besides, students who did not visit religious sites had reported higher number of life time sexual partners compared to those who visit regularly.[8] Moreover, there are evidences that males were more likely to have concurrent sexual partners than females.[9- 10, 14]. Only a few studies 
were done in Ethiopia on multiple sexual partnerships among governmental university and college students; however, there is no information regarding multiple sexual behaviors among students in private colleges.

Unlike governmental colleges and universities, where students accommodated in the campus, most of students of private colleges live in rented houses away from their supervising families, since most of them are from rural communities. These students might engage in risky sexual behaviours including multiple sexual partners because of different reasons including lack of family close supervision, peer pressure and locations of houses they rented could be near bars, khat chewing houses, night club houses and different other reasons. Therefore, the aim of this study was to assess the prevalence and associated factors of multiple sexual partnerships among private college students in Bahir dar city. The finding of this study is expected to contribute in filling the gap in understanding magnitude of multiple sexual partnerships and factors associated with multiple sexual partnerships among college students. Besides, the finding will contribute for the colleges to design better intervention strategies and educational programs. Moreover, individuals who interested in the field of sexual behaviors on higher education students in general would benefit from it.

\section{Methods and Materials}

Cross sectional quantitative study design was conducted among private college students of Bahir dar city in Oct. 2012. This study was conducted in northwest part of Ethiopia at a distance of 563 kilometers from capital city (Addis Ababa) among regular private college students in Bahir Dar city. There are eight private colleges in city which have regular programs with different fields of study; these private colleges are among many colleges in Amhara regional state in Northwest of the country.

Bahir dar city is the capital city of Amhara regional state and is one of the cities in Ethiopia in which investment is rapidly growing and educational investment is one of those investments currently raising; private colleges in the city host many students and are running different fields.

All regular students of private colleges in Bahir Dar city enrolled in 2011/12 academic year and were attending their education in the day program were eligible for this study.

The sample size was determined using single population proportion formula. The proportion of multiple sexual partner ship was determined based on previous study in Addis
Ababa University 37\% [15]. The following assumptions were used: level of confidence $95 \%$, a $5 \%$ marginal error. Based on these assumptions, the sample size was calculated as:

$\mathrm{n}=(\mathrm{Z} \alpha / 2)^{2} \mathrm{p}(1-\mathrm{p}) / \mathrm{w}^{2}$. Where; $\mathrm{n}=$ the minimum sample size needed, $\mathrm{P}=$ proportion of multiple sexual partner ships $(37 \%), \mathrm{w}=$ absolute precision $=0.05$ and $\mathrm{Z} \alpha / 2=1.96$ at confidence level $95 \%$. Then,

$\mathrm{n}=(1.96)^{2}(0.37 \times 0.63) /(0.05)^{2}=\mathrm{n}=359$. The final sample size with multistage design effect of 2 and $10 \%$ allowance for data incompleteness, the number of students included in the study were $[359 \times 2]+10 \%[359 \times 2]=[718$ +71.8 ] $=790$

The respondents were selected from target population through multistage sampling technique and Probability Proportionate to size of the students from each private college in the City. The calculated sample size 790 was distributed in to each private college proportional to the size of students. Departments were selected randomly from each college; then the sample size allocated to each college was distributed to each randomly selected department proportional to size of their students. The sample size allocated for each department again distributed to each year of study. Eventually, the required number of participants was chosen from each year of study by using simple random sampling methods from list of students.

Data were collected using self-administered structured questionnaire. The questionnaire was adopted from reviewed literatures, [16-18] and translated to local language Amharic. Pre-test was done on similar populations that are not included in the main survey and necessary changes were done to my questionnaire. It has four sections: $3.1 \&$ 3.2 socio- demographic characteristics of participants and their families, section 3.3 risk related factors of the study participants, and section 3.4 sexual behaviours of the study participants. My outcome measure was having multiple sexual partners in the last twelve months in section 3.4. The first question asked in this section was: "Have you ever had sexual intercourse?" the responses were "Yes" or "No". Individuals answered "Yes" were asked further questions "have you had sex in the last twelve months?" responses were "Yes" or "No" respondents answered "Yes" asked a next question "with how many sexual partners did you had sex in the last twelve months?" responses were "one", "two", "three", "four" and "more than four" but analyzed transforming the variable as response options of "one" and "more than one". Other questions such as condom use were also asked in this section (see table 4)

Table 4. Factors associated with multiple sexual practices of Private college students in Bahir dar city, Oct. 2012.

\begin{tabular}{lcccc}
\hline Variables & \multicolumn{3}{l}{ Multiple sexual partner } & OR(95\%CI for OR) \\
Ces & No & & Adjusted \\
\hline Sex & & & & \\
Male & 115 & 158 & $5.12(3.58-7.33)$ & $4.77(3.02-7.51)$ \\
Female & 62 & 435 & 1.00 & 1.00
\end{tabular}




\begin{tabular}{|c|c|c|c|c|}
\hline Age & & & & \\
\hline $15-19$ & 24 & 128 & 1.00 & 1.00 \\
\hline $20-24$ & 124 & 411 & $1.61(0.99-2.60)$ & $0.76(0.39-1.49)$ \\
\hline $\begin{array}{l}>24 \\
\text { Living condition }\end{array}$ & 29 & 53 & $2.81(1.50-5.26)$ & $0.66(0.27-1.59)$ \\
\hline Rented & 135 & 253 & $4.33(2.96-6.35)$ & $2.02(1.25-3.28)$ \\
\hline $\begin{array}{l}\text { Living with family } \\
\text { Years of study }\end{array}$ & 42 & 341 & 1.00 & 1.00 \\
\hline First year & 12 & 299 & 1.00 & 1.00 \\
\hline Second year & 72 & 165 & $10.87(5.73-20.62)$ & $7.27(3.53-14.99)$ \\
\hline $\begin{array}{l}\text { Third year } \\
\text { Frequ. of visiting religious sites }\end{array}$ & 93 & 130 & $17.83(9.44-33.65)$ & $9.23(4.52-18.83)$ \\
\hline Regularly & 30 & 254 & 1.00 & 1.00 \\
\hline Once or twice a week & 28 & 182 & $1.30(0.75-2.26)$ & $0.68(0.32-1.42)$ \\
\hline Some times & 107 & 148 & $6.12(3.89-9.63)$ & $1.23(0.65-2.33)$ \\
\hline $\begin{array}{l}\text { Never visit } \\
\text { Monthly pocket per month }\end{array}$ & 12 & 10 & $10.16(4.05-25.51)$ & $2.09(0.64-6.79)$ \\
\hline$<150$ birr & 45 & 191 & 1.00 & 1.00 \\
\hline 151-250 birr & 30 & 137 & $0.93(0.56-1.55)$ & $0.075(0.37-1.52)$ \\
\hline 251- 400 birr & 48 & 140 & $1.46(0.92-2.31)$ & $0.92(0.48-1.77)$ \\
\hline $\begin{array}{l}>401 \text { birr } \\
\text { Have a close friend started sex }\end{array}$ & 54 & 126 & $1.82(1.15-2.87)$ & $0.72(0.38-1.36)$ \\
\hline Yes & 146 & 180 & $10.83(7.08-16.57)$ & $5.99(3.66-9.81)$ \\
\hline $\begin{array}{l}\text { No } \\
\text { Khat use }\end{array}$ & 31 & 414 & 1.00 & 1.00 \\
\hline Yes & 73 & 66 & $5.62(3.79-8.33)$ & $1.38(0.82-2.31)$ \\
\hline $\begin{array}{l}\text { No } \\
\text { Alcohol intake }\end{array}$ & 104 & 528 & 1.00 & \\
\hline Yes & 106 & 88 & $8.58(5.89-12.51)$ & $3.20(2.02-5.08)$ \\
\hline $\begin{array}{l}\text { No } \\
\text { Shisha intake }\end{array}$ & 71 & 506 & 1.00 & 1.00 \\
\hline Yes & 19 & 18 & $3.848(1.973-7.507)$ & $0.70(0.29-1.71)$ \\
\hline No & 158 & 576 & 1.00 & 1.00 \\
\hline
\end{tabular}




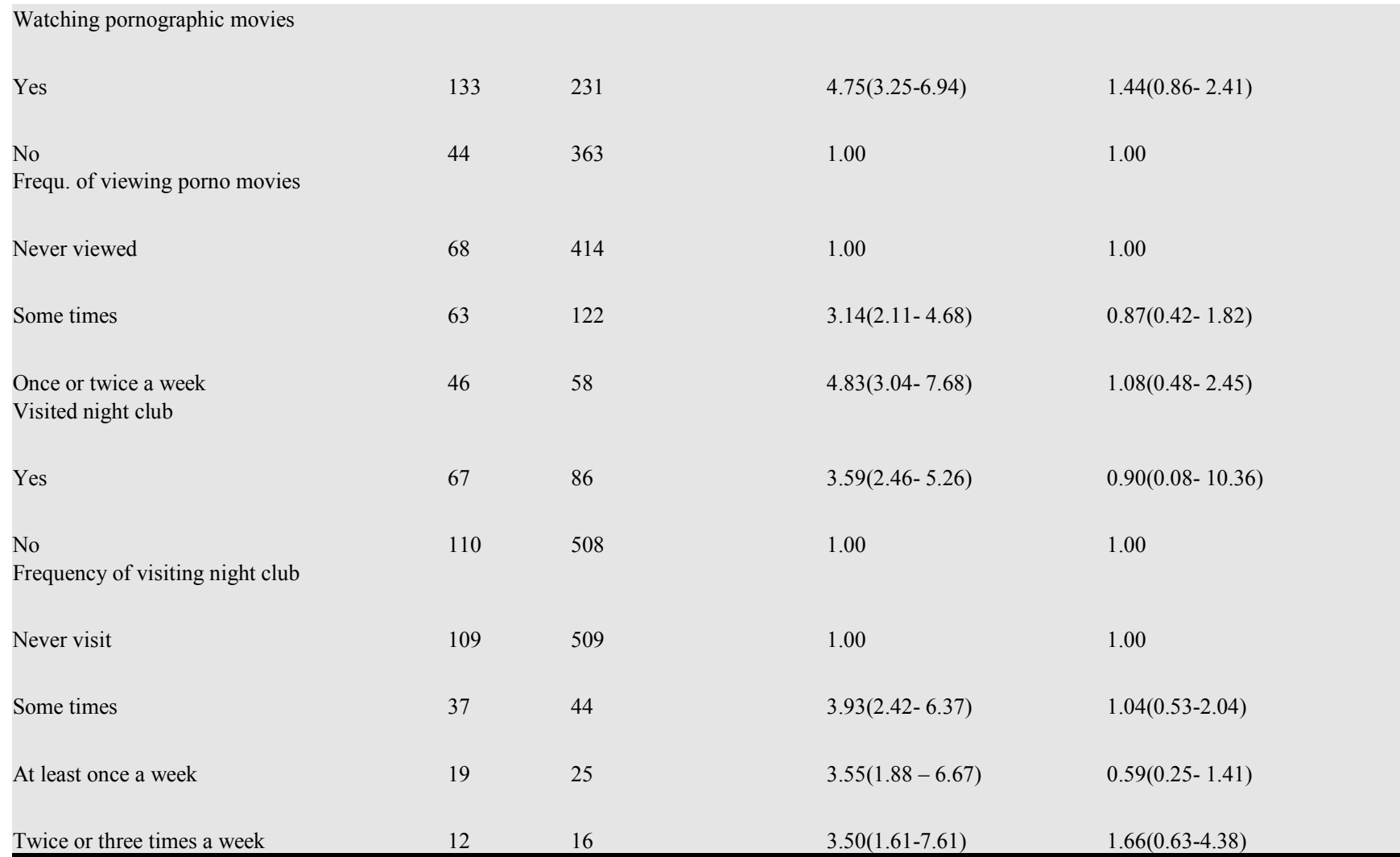

Seven post graduate students as data collection facilitators and the principal investigator as supervisor were recruited during the field work. During the time of data collection, data collection facilitators were assigned on the selected sections. The students selected in the given section were given a questionnaire with an envelope and requested to read the consent form carefully to get informed verbal consent before they were enrolled in the study.

Getting informed consent, the data collection facilitators oriented the students how to fill the questionnaires properly, then after they told go ahead to start filling the questionnaires. Moreover the data collection facilitators assisted the students on questions that students might encounter a problem and the principal investigator coordinate the over all process of the data collection. At the end the respondents put the completed questionnaires in the box ready for collection of questionnaires themselves.

The questionnaire was initially prepared in English and translated in to local language Amharic in order to obtain the required information from the respondents and was translated back to English to check for any inconsistencies or distortions.

Data collection facilitators were trained for two days to make them familiar with the questionnaires; the way how to orient and guide the study participants in filling the questionnaire format. Pre-test was done among 40 randomly selected students from Bahir Dar polytechnic college. The data collection was completed within one day to avoid information contamination.

Data were double-entered onto the EPI-data Version 3.1 software by defining legal values for each variable and setting skip patterns. The double-entered data were validated and exported to SPSS version 16 software package.

Univarate and Bivarate analysis were computed to see the frequency distribution and to test whether there is association/difference/ between risky sexual behaviour (multiple sexual partners and inconsistent condom use) and selected independent variables respectively. Factors associated with risky sexual practices at bivariate were identified and the variables with p-value of 0.20 and less were taken to multivariable analysis and the model was built with backward elimination. Finally, the p-values less than 0.05 were considered statistically significant.

Ethical clearance was obtained from ethical review committee of Bahir Dar University and communicated with regional health bureau before the time of data collection. Letter of permission was obtained from the health bureau and each college. The confidentiality of information was maintained by excluding personal identifiers; data were collected after securing informed consent from every respondent.

\section{Results}

\subsection{Socio-Demographic Characteristics of The Study Participants}

A total of 790 students completed the questionnaires of which 19 responses were excluded because of gross incompleteness and resulting a response rate of $97.6 \%$. Out of the total respondents $498(64.6 \%)$ were females. More 
than four fifth of the respondents (84.7\%) were never married. The mean $\pm \mathrm{SD}$ age of the study population was $21.5 \pm 2.44$ years. Slightly more than half of the respondents $(52.9 \%)$ were living alone in rented house without their family and the rest were living with family. Four hundred fifty nine $(59.5 \%)$ and $312(40.5 \%)$ of the study participants were attending their education in health and non health fields respectively.

Three hundred eleven (40.3\%), 237(30.7\%) and $223(28.9 \%)$ respondents were year one, two and three respectively. Moreover the study indicated that $36.8 \%, 27.2 \%$, $33.1 \%$, and $2.9 \%$ of respondents were visiting religious institutions regularly, once or twice a week, some times and never visited religious institutions respectively. And more than half of the respondents $(52.5 \%)$ got pocket money below average 296 Ethiopian birr per month, while $180(23.3 \%)$ of the respondents got above 400 birr per month. Moreover 345(44.7\%) and $159(20.6 \%)$ of the participants' mothers and fathers were Illiterate respectively; and $313(61.5 \%)$ participant's family monthly income was below the average 2523 Ethiopian birr while $118(23.1 \%)$ participants' families earn more than 3000 Ethiopian birr per month.

In terms of discussion on sexual issues between families and the study participants, only $216 \quad(28.0 \%)$ and $143(18.5 \%)$ of respondents discussed on sexual issues with their mothers and fathers respectively (table 1).

Table 1. Socio demographic characteristics of college students in Bahir dar city, Oct. 2012.

\begin{tabular}{lll}
\hline Variables (N=771) & Categories & Total n (\%) \\
\hline Sex & Male & $273(35.4)$ \\
& Female & $498(64.6)$ \\
Age & $15-19$ & $152(19.7)$ \\
& $20-24$ & $535(69.4)$ \\
Marital status & $>24$ & $84(10.9)$ \\
Living circumstance & Married & $118(15.3)$ \\
& Single & $653(84.7)$ \\
Freq. of visiting religious & Rented & $388(50.3)$ \\
Sites & With family & $383(49.7)$ \\
& Regularly & $284(36.8)$ \\
& Onc/ twice a week & $210(27.2)$ \\
Pocket money per month & Some times & $255(33.1)$ \\
& Never visit & $22(2.9)$ \\
& $<150$ birr & $236(30.6)$ \\
& $150-250$ birr & $167(21.7)$ \\
& $251-400$ birr & $188(24.4)$ \\
& $>400$ birr & $180(23.3)$ \\
Mothers education level & Illiterate & $345(44.7)$ \\
& Read and write & $245(31.8)$ \\
& 1-8 grade & $89(11.5)$ \\
& $9-12$ grade & $55(7.1)$ \\
& Diploma and above & $37(4.8)$ \\
& Illiterate & $159(20.6)$ \\
& Read and write & $284(36.8)$ \\
& $1-8$ grade & $115(14.9)$ \\
& $9-12$ grade & $115(14.9)$ \\
& Diploma and above & $98(12.7)$ \\
\hline
\end{tabular}

\begin{tabular}{lll}
\hline & $<1500$ & $151(29.7)$ \\
& $1500-2000$ & $132(26)$ \\
Monthly family income(509) & $2001-3000$ & $108(21.2)$ \\
& $>3000$ & $118(23.1)$ \\
& & \\
& Yes & \\
$\begin{array}{l}\text { Discussion of sexual } \\
\text { issues with mother }\end{array}$ & No & \\
& Don't remember & \\
Discussion of sexual & Yes & $216(28)$ \\
issues with father & No & $543(70.4)$ \\
& Don't remember & $12(1.6)$ \\
& & \\
\hline
\end{tabular}

\subsection{Risk Related Factors for Multiple Sexual Partners among College Students of Bahir Dar City}

Out of the total 771 respondents 326(42.3\%) were reported to have peer pressure to start ex and have sexual partners. Alcohol and Khat were the most frequently used substances. Accordingly out of the total respondents 194(25.0\%) alcohol, 139(18.0\%) Khat, 37(4.8\%) shisha and $15(1.9 \%)$ were Cigarette users; Of the total substance users 33 respondents $16(48.5 \%)$ males and $17(51.5 \%)$ females were reported to use regularly and 57 respondents $29(51.0 \%)$ males and $28(49 \%)$ females were used once or twice a week. One hundred sixty two $(54.5 \%)$ males and 202(55.5\%) females were exposed to pornographic movies. Besides, 153(19.2\%) of total respondents were confessed to attend night clubs; of these night club attendants $28(18.3 \%)$ visited once or twice a week and 44(28.7\%) of them were attended at least once a week.

Table 2. Percentage distributions of risk related factors for multiple sexual partners among college students in Bahir dar city, Oct. 2012.

\begin{tabular}{|c|c|c|c|}
\hline $\begin{array}{l}\text { Risk related factors }(N=771) \\
\text { Sex of the respondent } s\end{array}$ & Male & Female & Total n (\%) \\
\hline \multicolumn{4}{|l|}{ Peer pressure } \\
\hline Yes & $145(44.5$ & $181(55.5)$ & $326(42.3)$ \\
\hline No & $128(28.8)$ & $317(71.2)$ & $445(57.7)$ \\
\hline \multicolumn{4}{|l|}{ Khat use } \\
\hline Yes & $72(51.8)$ & $67(48.2)$ & $139(18)$ \\
\hline No & 201(31.8) & $431(68.2)$ & $632(82)$ \\
\hline \multicolumn{4}{|l|}{ Alcohol use } \\
\hline Yes & $100(51.5)$ & $94(48.5)$ & 194(25.2) \\
\hline No & $173(30)$ & $404(70)$ & $577(74.8))$ \\
\hline \multicolumn{4}{|l|}{ Shisha use } \\
\hline Yes & $21(56.8)$ & $16(43.2)$ & $37(4.8)$ \\
\hline No & $252(34.3)$ & $482(65.7)$ & $734(95.2)$ \\
\hline \multicolumn{4}{|l|}{ Frequency of using substances } \\
\hline Regularly & $16(48.5)$ & $17(51.5)$ & $33(4.3)$ \\
\hline Once or twice a week & $29(50.9)$ & $28(59.1)$ & $57(7.4)$ \\
\hline Some times & $91(51.4)$ & $86(48.6)$ & $177(22.96)$ \\
\hline Never use & 137(27.2) & $367(72.8)$ & $504(65.3)$ \\
\hline \multicolumn{4}{|l|}{ Viewed pornographic movies } \\
\hline Yes & $162(54.5)$ & $202(55.5)$ & $364(47.2)$ \\
\hline No & $111(27.3)$ & $296(72.7)$ & $407(52.8)$ \\
\hline \multicolumn{4}{|l|}{ Frequency of viewing } \\
\hline Never viewed & $48(46.2)$ & $56(53.8)$ & $104(13.5)$ \\
\hline
\end{tabular}




\begin{tabular}{llll}
$\begin{array}{l}\text { Once or twice a week } \\
\text { Some times }\end{array}$ & $81(43.8)$ & $104(56.2)$ & $185(24)$ \\
& & & \\
Visited night club & & & \\
Yes & $71(46.4)$ & $82(53.6)$ & $153(19.8)$ \\
No & $202(32.7)$ & $416(67.3)$ & $618(80.2)$ \\
Frequency of visiting night & & & \\
club & $202(32.7)$ & $416(67.3)$ & $618((79.5)$ \\
Never visit & $40(49.4)$ & $41(50.6)$ & $81(10.5)$ \\
Some times & $23(52.3)$ & $21(47.7)$ & $44(5.7)$ \\
At least once a week & $8(28.6)$ & $20(71.4)$ & $28(3.63)$ \\
Once or twice a week & & & \\
\hline
\end{tabular}

\subsection{Sexual Behaviours of Private College Students in Bahir Dar City}

This study indicated that out of the total respondents, $391(50.7 \%)$ ever had sexual intercourse. The mean age at sexual commencement for both sexes was 18.7 years with standard deviation of 1.97. Higher number of female respondents $118(63.4 \%)$ had sex before they were being 18 years. The study revealed that 356 students $43.3 \%$ males and $56.9 \%$ females had sex in the last 12 months. One hun- dred fifteen (65.0\%) males and 140(35\%) females, had sex with more than one sexual partner in past 12 months. The study further pointed out that only $45(11.5 \%)$ respondents had used condom in their first sex. Moreover with regard to the frequency of condom use, 231(59.0\%) sexually active respondents were reported to use condom consistently, however; $106(27.0 \%)$ and $44(11.3 \%)$ of sexually active respondents acknowledged to use condom occasionally and never during their sexual activities respectively. Among respondents who were not using condom consistently disclosed the reason why they failed to use was that, $113(44.4 \%)$ reported condom decreases sexual pleasure, $73(28.7 \%)$ described fear of side effects and 47(18.5\%) because of religious reason. Besides, findings of this study declared that among respondents who didn't initiated sexual intercourse; about $59.7 \%$ reported delayed sex to wait until marriage, $30 \%$ fear of HIV/AIDS and $8.2 \%$ because of religious reason (Table 3).

Table 3. Sexual behaviours of private college students in Bahir dar city, Oct. 2012.

\begin{tabular}{|c|c|c|c|}
\hline \multirow[t]{2}{*}{ Characteristics of Respondents } & \multicolumn{2}{|c|}{ Sex of respondents } & \multirow[t]{2}{*}{ Total n (\%) } \\
\hline & Male & Female & \\
\hline \multicolumn{4}{|l|}{ Ever had sexual intercourse $(\mathrm{n}=771)$} \\
\hline Yes & $169(43.2)$ & $222(56.8)$ & $391(50.7)$ \\
\hline No & $104(27.4)$ & $276(72.6)$ & $380(49.3)$ \\
\hline \multicolumn{4}{|l|}{ Age at first $\operatorname{sex}(391)$} \\
\hline$<18$ years & $68(36.6)$ & $118(63.4)$ & $186(47.6)$ \\
\hline$>=18$ years & $100(49.0)$ & $105(51.0)$ & $205(52.4)$ \\
\hline \multicolumn{4}{|c|}{ Ever had sex in the last 12 months $(n=391)$} \\
\hline Yes & $154(43.3)$ & $202(56.7)$ & $356(91.0)$ \\
\hline No & $15(42.9)$ & $20(57.1)$ & $35(9.0)$ \\
\hline \multicolumn{4}{|c|}{ Number of sexual partner in the last 12 months(391) } \\
\hline One & $39(21.8)$ & $140(78.2)$ & $179(45.8)$ \\
\hline More than one & $115(65.0)$ & $62(35.0)$ & $177(45.3)$ \\
\hline \multicolumn{4}{|l|}{ Used condom in the first $\operatorname{sex}(n=391)$} \\
\hline Yes & $24(53.3)$ & $21(46.7)$ & $45(11.5)$ \\
\hline No & $143(41.9)$ & $198(58.1)$ & $341(87.2)$ \\
\hline \multicolumn{4}{|l|}{ Frequency of condom use $(\mathrm{n}=391)$} \\
\hline Regularly & $102(44.2)$ & $129(55.8)$ & $231(59.0)$ \\
\hline Some times & $43(40.6)$ & $63(59.6)$ & $106(27.0)$ \\
\hline Never & $21(47.7)$ & $23(52.3)$ & $44(11.3)$ \\
\hline \multicolumn{4}{|l|}{ Reason not use condom $(\mathrm{n}=255)$} \\
\hline Lack of information & $5(45.5)$ & $6(54.5)$ & $11(4.3)$ \\
\hline Cultural taboo & $4(40.0)$ & $6(60.0)$ & $10(3.93)$ \\
\hline Religious reason & $19(40.4)$ & $28(59.6)$ & $47(18.5)$ \\
\hline Fear of side effects & $25(34.2)$ & $48(65.8)$ & $73(28.7)$ \\
\hline Decreases pleasure/satisfaction & $49(43.4)$ & $64(56.6)$ & $113(44.4)$ \\
\hline \multicolumn{4}{|c|}{ Reason not have sex until study period $(n=375)$} \\
\hline Fear of AIDS/other STD'S & $41(35.7)$ & $74(64.3)$ & $115(30.3)$ \\
\hline Fear of family & $1(50.0)$ & $1(50.0)$ & $2(0.5)$ \\
\hline Because of religious reason & $12(38.7)$ & $19(61.3)$ & $31(8.2)$ \\
\hline Need to wait until marriage & $42(18.5)$ & $185(81.5)$ & $227(59.7)$ \\
\hline
\end{tabular}

\subsection{Logistic Regression Analysis between Multiple Sexual Partners and Predictor Variables among Private Col- lege Students in Bahir Dar City, Oct. 2012}

The multivariate analysis result (table-4) indicated that sex, current residence of the students (rented or living with family), years of study, peer pressure, and alcohol consumption were statistically significant with multiple sexual 
partners. However; age, religiosity, pocket money, Khat use, shisha use, viewing pornographic movies, attending night club and frequency of attending it were associated with multiple sexual partners on bivarate analysis but couldn't persist in having such association in the multivariate analysis.

The multivariate analysis result, revealed that the odds of having multiple sexual partners among males was more than four times compared to females $(\mathrm{AOR}=4.76$; $\mathrm{CI}$ : 3.02-7.51), and students who were living alone in rented house were about two times more at risk to have multiple sexual partners $(\mathrm{AOR}=2.02 ; \mathrm{CI}: 1.25-3.27)$ compared to student who live with their family.

There is strong positive association between year of study and having multiple sexual partners, it was found that year two and three students were more likely to have higher number of multiple sexual partners compared to year one students $(\mathrm{AOR}=7.27$; $\mathrm{CI}: 3.53-14.99)$ and $\mathrm{AOR}=9.23$; CI: 4.52-18.83) respectively.

Peer pressure was the other independent predictor factor for having multiple sexual partners; students who had peer pressure were about six times more likely to have multiple sexual partners compared to those who don't have (AOR = 5.99; CI:3.66-9.81).

Besides, this study indicated that there was statistically significant association between alcohol intake and having multiple sexual partners, respondents who ever drank alcohol were more than three times risk of having multiple sex partners (AOR $=3.20 ; \mathrm{CI}: 2.02-5.08)$ ) compared to those who never drank.

\section{Discussion}

The aim of this study was to assess the prevalence and correlates of multiple sexual partners for HIV infections among college students in Bahir dar city. Adolescents and young adults have increased interest in the opposite sex and are frequently changing relationships.[7] Moreover, higher education students were engaged in risky sexual behaviours that could placed them at higher risk for HIV/AIDS.[9, 15]

Accordingly the findings of this study indicated that $50.7 \%$ of the respondents were sexually active and this is consistent with similar studies done in southern Ethiopia where the figure was $49 \%$ (19) and 54\% in Uganda for both sexes.[20]

The prevalence of multiple sexual partner and unprotected sex among sexually debuted respondents of this study were $45.3 \%$ and $38.4 \%$ respectively and this finding was consistent with Tanzanian higher education students, where multiple sexual partner and unprotected sex were $42 \%$ and $39.2 \%$ respectively.[21] Whereas our finding was not in accordance to among AAU students, where multiple sexual partner and unprotected sex were being $37 \%$ and $29 \%$ respectively,[15] and among higher education students of Cambodia where multiple sexual partners and unprotected sexual intercourse were $36 \%$ and $52.6 \%$ respectively.[22]

In our study the prevalence of multiple sexual partners and unprotected sex are slightly higher compared to AAU university students; this could be because of private college students are not living in a campus rather most are living in a rented house away from their supervising family and the house they may rented could be near bars, night clubs and video houses; which could initiate substance use and attend the mentioned sites.

Students who were living in rented house without their supervising family were about two times more likely to have multiple sexual partners compared to those who were living with their family. The reason could be peer pressure, students who are living in rented house with no family member pass most of their time with intimate friend but this could have result to share bad behaviour such as alcohol and Khat use, in turn substance use could initiate sexual desire and result to have multiple sexual partners and other possible reason could be living free of family control by itself creates a room to initiate sex and have multiple sexual partners.

The findings of this study revealed that male respondents were more than four times likely to have multiple sexual partners than females and this is consistent with Tanzanian college students, where males were two times more likely to have multiple sexual partners.[21] This finding and similar studies indicated that males were more likely to be engaged to have multi sexual partners than females; according to the current study the reason could be substance use such as khat and alcohol were more common in males and out of the total respondents who visit religious institutions regularly $69 \%$ were females indicating higher levels of religiosity is associated with fewer sexual partners in females, this is in accordance with other studies.[21-22] Where religiousness seems to be a protective factor against a high number of sexual partners among females.

This study further declared that year two and three students were more than seven and nine times more likely to have multiple sexual partners respectively compared to year one, this justifies that as year of study increases the risk of having multiple sexual partners increases, this might be because of alcohol use, peer pressure and increased level of extroversion. Accordingly the finding of this study indicated that the percentage of alcohol use out of the total users among year one, two and three students respectively were $14.9 \%, 36.1 \%$ and $49 \%$.

Peer pressure was the other predictor variable which showed statistically significant association with multiple sexual partnerships; individuals who had peer pressure to initiate sex and have sexual partners were more than 5 times risk of having multiple sexual partners compared to those who didn't have. This is consistent with other studies.[23] This indicates that the students are not only sharing their knowledge on their education with each other but also their risky sexual behaviours. Besides, most private college students in Ethiopia are living neither with their family nor in a campus, rather they live in rented houses with their intimate friend from whom they share both good and bad behaviours. 
The findings of this study further explored that respondents who were using alcohol were more than three times likely to have multiple sexual partners compared to non users, this is in line with study done among Slovakian college and Lund university students where alcohol consumption was associated with higher risk for having higher number of sexual partners.[11,24] This could be due to risk perception ability decreases with alcohol consumption; indicating that individuals who use alcohol were more likely to get infected with HIV/AIDS and other sexually transmitted infections.[25] All the above findings clearly and alarmingly indicate that private college students were engaged in multiple sexual partnerships and at risk of HIV/AIDS infection which require attention from the concerned bodies.

\section{Strengths}

The prevalence and predictor variables of multiple sexual partnerships of college students were identified. Simple and straight methods of study were under taken.

The reliability of the data was maintained by pretest of the questionnaires on similar population, prior training of the data collectors and supervisors. Besides, probability multistage sampling technique was employed to select the study units from all eight private colleges to minimize bias. Moreover, appropriate tests were employed and findings were compared with other related studies locally and internationally.

\section{Limitation}

Even though multiple sexual partnerships is one of sensitive issue of sexual behaviours, this study contains only quantitative component, it didn't triangulated qualitatively and the study was based on cross-sectional data, which means that the direction of causal relationships between multiple sexual partnerships and predictor variables can't be determined. In addition, despite self administrated questionnaire was used, which gave greater right to respond freely to get a valid data on this sexual sensitive issue; still social desirability bias might not be eliminated.

\section{Conclusion}

Large proportions of students were engaged in multiple sexual partners. Factors such as sex, year of study, religiosity, peer pressure, and alcohol use among college students were associated with multiple sexual partners. Therefore the following recommendations were given for the concerned bodies:

Concerned bodies; Anti- AIDS clubs of the college, government organizations and non-government organizations need to teach on the consequences of concurrent sexual partners.

Religious leaders need to give attention to make students regularly visit religious services and teach them on the po- tential consequences of having concurrent sexual partners.

Peers have greater influence on the positive and negative behavior of their friends. In order to protect college youth from risky behaviors, Colleges should focus in promoting peer educators and the way for peer discussion.

Based on the association between substance use with multiple sexual partners, Colleges and other concerned bodies need to focus on teaching the prevention of substance use.

Waiting until marriage is one of the means to delay sex and not to have risky sex such as concurrent sexual partner ships. Therefore, teaching college youth to delay sex enables them not to be engaged in multiple sexual practices.

\section{Acknowledgements}

I thank to all private colleges in Bahir Dar city involved, data collectors and supervisors of the study; finally my special gratitude goes to the participants of the study who shared their time to fill the questionnaire and give their genuine responses.

This study was funded by a grant from Bahir Dar University.

\section{Contributors}

I don't have any contributors to this study.

\section{Computing Interests}

I declared that I don't have any computing interests.

\section{References}

[1] PSI healthy lives measurable results. Concurrent Sexual Partnerships, [Accessed 4 Jan 2013]. Available from: http://www.psi.org/our-work/healthy-

lives/interventions/multiple-concurrent-partnerships

[2] USIADS. Behavioral Interventions: Multiple and Concurrent Sexual Partnerships. [Updated March 2011; Accessed 10 Feb 2013]. Available from: http://www.aidstarone.com/focus_areas/prevention/pkb/eme rging_areas/multiple_and_concurrent_sexual_partnerships.

[3] Mishra, V, and Simona BVA. 2009. Concurrent Sexual Partnerships and HIV Infection: Evidence from National Population-Based Surveys. DHS Working Papers No. 62. Calverton, Maryland: Macro International Inc.

[4] Recommendations from a meeting of the UNAIDS Reference Group on Estimates, Modelling and Projections held in Nairobi, Kenya, April 20-21st 2009. Consultation on Concurrent Sexual Partnerships. Revised: 30 November 2009.

[5] Almon S, John M and Jacqueline C. The Concurrent Sexual Partnerships among students in Institutions of Higher Education in Zimbabwe. J Hum Ecol 2011; 34: 53-65.

[6] Joint United Nations Programme on HIV/AIDS (UNAIDS) world AIDS day report 2011. 
[7] Jenny Nicholson MSW Student, risky sexual behaviour among adolescents and young adults, University of North Carolina Chapel Hill, [Accessed 4 may 2012]. Available from: http://www.docstoc.com/docs/38043379/

[8] Agardh A, Tumwine G, and O"stergren P-O. The Impact of Socio-Demographic and Religious Factors upon Sexual Behavior among Ugandan University Students. PLoS ONE 2011; 6: e23670. doi:10.1371/journal.pone.0023670.

[9] Sunmola AM. Evaluating the sexual behaviour, barriers to condom use and its actual use by university students in $\mathrm{Ni}$ geria. AIDS Care 2005; 17: 457-465.

[10] Amon E, Angelina ML, Godfrey M, et al. Multiple sexual partners and condom use among youths in four districts in Tanzania: What do we learn? BMC Public Health 2011, $11: 490$.

[11] Anette A, Karen OP and Per-Olof O. Experience of sexual coercion and risky sexual behavior among Uganda university students. BMC Public Health 2011, 11:527.

[12] Seth C. Kalichman. Multiple-Recent Sexual Partnerships and Alcohol Use among sexually transmitted infection clinic patients. Sex Transm Dis. 2011; 38:18-23.

[13] Hibret A, Damen H, Kassahun A, et al. Factors Predisposing out-of-School Youths to HIV/AIDS-related Risky Sexual Behaviour in Northwest Ethiopia. J HEALTH POPUL NUTR 2007; 25:344-350.

[14] Vinod M and Simona BVA. USAIDS, DHS working papers 2009; Concurrent Sexual Partnerships and HIV Infection: Evidence from National Population Based Surveys.

[15] Nigatu R, Seman K. Attitudes and practices on HIV preventions among students of higher education institutions in Ethiopia. Educational Research 2011; 2: 828-840.

[16] Abdulhakim H. Factors promoting risky sexual behaviour of high school adolescents in Dessie town, Amhara regional state (thesis). Institute of Population Studies, College of De- velopment Studies, School of Graduate Studies Addis Ababa University, 2008.

[17] Jemal Yousuf. Assessment of risky sexual behaviour for HIV infection with special focus on night markets and mobile people in Gunner woreda, Gurage zone (thesis). School of public health, Faculty of Medicine Addis Ababa university, Ethiopia, 2004.

[18] Anemaw A. Assessment of sexual risk behaviours of inschool youth: effect of living arrangement of students; West Gojam zone, Amhara regional state, (thesis). School of public health, Faculty of Medicine Addis Ababa University, Ethiopia, 2009.

[19] Zerai K . Sexual Experiences and their Correlates Among Jimma University Students, Jimma, Ethiopia. Ethiop. J. Health Sci 2002; 15: 21-29.

[20] Najjumba M.I, Ntozi.J, Ahimbisibwe E.F, et al. Risk perception and condom use in Uganda. African population studies 2003; 18: 68-80

[21] Maswanya.ES, Moji.K, Horiguchi.I, et al. Knowledge, risk perception of AIDS and reported sexual behaviour among students Tanzanian colleges. Health education research 1999;14:185-196.

[22] Siyan Y, KrishnaC.P, Junko Y, et al. Role of risk and protective factors in risky sexual behavior among high school students in Cambodia. BMC Public Health 2010, 10:477.

[23] Robert J, Ali M, Lisa A, et al. Reproductive Health Risk and Protective Factors among Youth in Lusaka, Zambia. J.Adolesc Health 2002; 30:76-86.

[24] Ondrej.K, AndreaM.G, Pavol.J, et al. Psychological and behavioural factors associated with sexual risk behaviour among Slovak students. BMC public Health 2009, 9:15.

[25] Alcohol Use and Sexual Risk Behaviour: A Cross-Cultural Study in Eight Countries. World Health Organization Geneva 2005. 